\title{
Reportagem
}

\section{Brasil e França debatem a profissionalização do serviço público}

Países com história e geografia bem peculiares. Nações que apresentam opções políticas, econômicas e culturais também diferentes. À primeira vista, para olhares desavisados, França e Brasil parecem ocupar posições tão distantes que não favoreceriam o diálogo. No entanto, ao contrário do que uma análise superficial aparenta, os dois Estados compartilham opiniões em muitos aspectos, especialmente em relação à democracia e à promoção da justiça social.

Em busca de aprofundar essas relações bilaterais é que se celebra, em 2009, o Ano da França no Brasil. Desde o mês de abril, são realizados eventos comemorativos em diversas áreas, com apoio dos estados brasileiros e das regiões e municípios franceses. O tema da construção de um serviço público qualificado como fator essencial à consolidação de nações democráticas não poderia ficar de fora dessa agenda francobrasileira. Afinal, o acesso a serviços públicos, para ambos os países, significa mais do que uma responsabilidade estatal; trata-se de um direito de cidadania.

Resultado da parceria entre a Escola Nacional de Administração Pública (ENAP) e a Ecole Nationale D'Administration (ENA), o Fórum Brasil-França trouxe à tona o debate da "profissionalização e consolidação do serviço público no contexto de reforma das políticas públicas". De 14 a 16 de setembro, estiveram reunidos, na ENAP, em Brasília, dirigentes de escolas de governo, além de lideranças governamentais, francesas, brasileiras e também de nações latino-americanas.

A proposta, apoiada pela Embaixada da França no Brasil, era a de criar um espaço de aprendizagem e compartilhamento de visões sobre democratização do serviço público, coordenação de políticas públicas e profissionalização da formação. As falas dos participantes, no encerramento da atividade, demonstravam que o objetivo do fórum havia sido alcançado com êxito. "Poucos dos exercícios bilaterais já estabelecidos, entre Brasil e França, foram tão satisfatórios quanto este", sintetizou Phillippe Bastellica, diretor de Relações Internacionais da ENA.

Durante o Fórum Brasil-França, as escolas de governo manifestaram a intenção de fortalecer o trabalho em rede e produzir conhecimento conjunto. A presidente da ENAP, Helena Kerr do Amaral, destacou a importância de inovar e definir métodos que possibilitem desenvolver competências para a tomada de decisão no tempo em que a sociedade exige. "As escolas devem fomentar a formação de dirigentes capazes 
de criar, nos ambientes de trabalho, espaços criativos, o que não é a regra da burocracia, marcada pela aversão ao risco", disse.

Para Bastellica, a troca mútua de experiências é, sem dúvida, o principal ganho de eventos com esse formato: "Podemos nos conhecer melhor através do olhar do outro. Trata-se de emprestar, aos nossos parceiros, não produtos acabados, mas ferramentas que nos ajudarão a construir nossos próprios projetos".

Nas próximas páginas, confira a síntese dos debates realizados no Fórum Brasil-França. Como a intenção era compartilhar as diferentes características, as três temáticas do evento foram discutidas em conferências ministradas por especialistas dos dois países em cada assunto. A palestra inaugural foi proferida por Jacky Richard, conselheiro de Estado da França. (Leia a íntegra da conferência na página 315).

\section{Como democratizar o serviço público?}

Essa questão foi debatida no segundo dia do Fórum Brasil-França pelo ministro Fernando Haddad, da Educação, e por
Gilles J. Guglielmi, professor de Direito Público da Universidade Paris II.

A ideia de democratizar o serviço público, na opinião de Guglielmi, parece paradoxal, visto se tratar de característica, de certa forma, inerente ao setor. "Podemos dizer que a noção de serviço público é democrática por essência. O problema reside no contato cotidiano com o usuário, no funcionamento e na organização da atividade. É preciso focar nessas questões mais precisas", explicou.

De acordo com o professor, no serviço público francês a democracia participativa é incentivada. Mesmo exercida ainda de forma difusa (por associações de bairro e sindicatos, entre outros), há o reconhecimento do cidadão como ator que deve contribuir na elaboração das políticas públicas e também na avaliação.

Gilles Guglielmi considera estratégico, para a manutenção dos serviços públicos, o diálogo permanente entre o usuário, no seu desejo de igualdade e cidadania, e o agente público, com seu ideário profissional e senso de prestação de serviços à população.

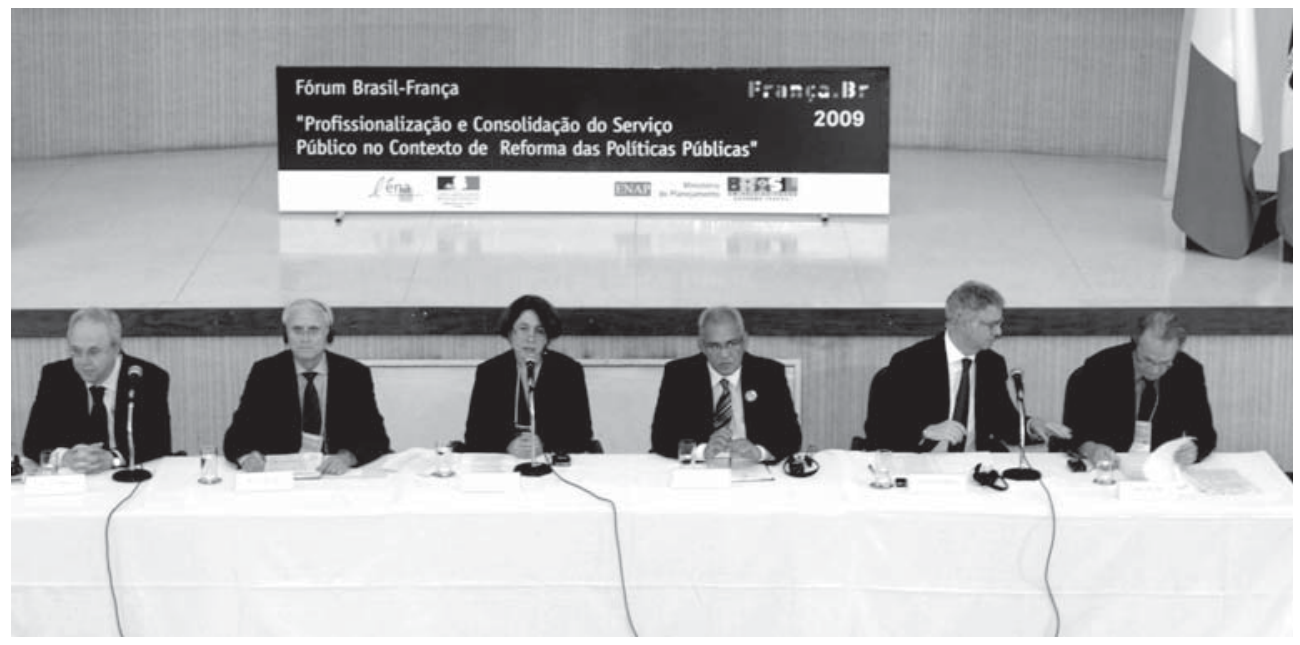

Solenidade de abertura reúne lideranças da administração brasileira e francesa. 
O ministro da Educação, Fernando Haddad, destacou que assegurar a participação popular no serviço público brasileiro demanda um processo de reorganização do Estado e de mudança de paradigmas, no sentido de desenvolvimento e implementação de políticas públicas.

Para ele, a história do país, marcada pela alternância de oligarquias no poder, dificultou a criação de uma burocracia profissionalizada, com a formação técnica necessária à elaboração de projetos políticos. "Estados oligárquicos podem organizar-se de modo a atender à legitimidade e aos clamores sociais, mas a natureza não segue uma lógica republicana e, sim, contábil, que mede as consequências das políticas públicas à luz do sucesso eleitoral", afirmou.

Haddad acredita que, para democratizar o serviço público, é imprescindível facilitar o acesso à educação, especialmente ao ensino superior: "Sem democratizar o serviço público deste ponto de vista, constituindo-o de pessoas vindas de todas as camadas sociais, jamais será possível a consolidação de uma burocracia estatal capaz de estabelecer processos de tomada de decisão permeáveis às demandas de todos os extratos sociais".

Nos debates após as conferências, os participantes do fórum demonstraram preocupação com a formulação de políticas que ampliem o acesso da sociedade à administração pública e selecionem servidores atentos às realidades nacionais. "É uma questão de eficiência administrativa poder recrutar em todas as camadas sociais", afirmou Bernard Boucault, diretor da ENA. Para Laura Parente, professora e doutoranda do Laboratoire Techiniques, Territoires et Sociètés-Latts, da Université de Marne-la-Vallée, "isso depende também da ampliação dos processos de formação para o conjunto dos funcionários públicos em todos os níveis de governo".

\section{O desafio da coordenação de políticas}

As diferenças e semelhanças entre as formas de coordenação de políticas públicas foram retratadas na terceira conferência do Fórum Brasil-França, realizada no dia 15 de setembro. Enquanto os dilemas franceses foram apresentados por Jean-Marc Ribière, membro do Conselho Superior da Administração Territorial do Estado, a subchefe de Articulação e Monitoramento da Casa Civil da Presidência da República, Miriam Belchior, explicou os desafios do modelo brasileiro.

A preocupação com a coordenação de políticas, segundo Ribiére, começou a despontar na França, nos anos 1990, diante da observação de que os serviços públicos, devido à excessiva fragmentação, não alcançavam todos os cidadãos. Para superar o quadro de desigualdade, o Estado francês percebeu a necessidade de rever o modelo de intervenção para dar mais força à ação pública, reduzir as diferenças entre os territórios e garantir a inclusão social.

Entre os desafios da coordenação de políticas, Jean-Marc apontou a necessidade de despertar o interesse dos órgãos federais para o trabalho em conjunto, utilizando uma abordagem em que todos ganham: "Se queremos implementar uma coordenação, precisamos ter um fundo interministerial, com recursos suplementares, a fim de fazer com que os ministérios se inscrevam em uma abordagem de aproximação".

O representante do Conselho Superior da Administração Territorial defendeu 
também a necessidade de abrir a coordenação de políticas a novos atores modernos, entre eles as fundações, as grandes associações, a sociedade civil.

Já a subchefe de Articulação e Monitoramento da Casa Civil, Miriam Belchior, analisou o tema da coordenação de políticas públicas sob duas dimensões: horizontal, dentro do próprio governo federal; e vertical, com estados e municípios. Para ela, enfrentar esse desafio demanda, ao mesmo tempo, uma postura de liderança dos dirigentes e de sensibilização das equipes para trabalhar de forma articulada. "Se o corpo dirigente não der sinais claros nessa direção, é muito difícil mudar a lógica setorial", considerou.

Igualmente importante, segundo Miriam, é fomentar a cooperação e a integração de ações entre órgãos da administração federal. O desafio é saber equilibrar a informalidade dos grupos de trabalho interministeriais e a formalização que determina quem será responsável pela política.

$\mathrm{Na}$ avaliação da representante da Casa Civil, as articulações de caráter regional ainda estão pouco desenvolvidas no Brasil. "É necessário constituir mecanismos para articulação das políticas das três esferas de governo, utilizando, inclusive, as tecnologias de comunicação".

Miriam Belchior também indicou, como elementos essenciais do trabalho coordenado: a definição clara das responsabilidades individuais e dos resultados que se pretende alcançar; e a manutenção do entusiasmo das equipes envolvidas.

\section{Profissionalizar a administração para qualificar os serviços públicos}

O último dia do Fórum Brasil-França foi dedicado à profissionalização dos servidores públicos. A diretora de Formação da Ecole Nationale D'Administration (ENA), Françoise Camet, e o secretário executivo adjunto do Ministério do Planejamento, Orçamento e Gestão, Francisco Gaetani, discorreram sobre a temática.

Ao apresentar a proposta adotada pela ENA, Françoise Camet explicou que o foco da formação oferecida pela escola francesa é preparar os funcionários de alto escalão para as futuras responsabilidades em um mundo que está sempre em evolução. Segundo ela, o atual modelo foi

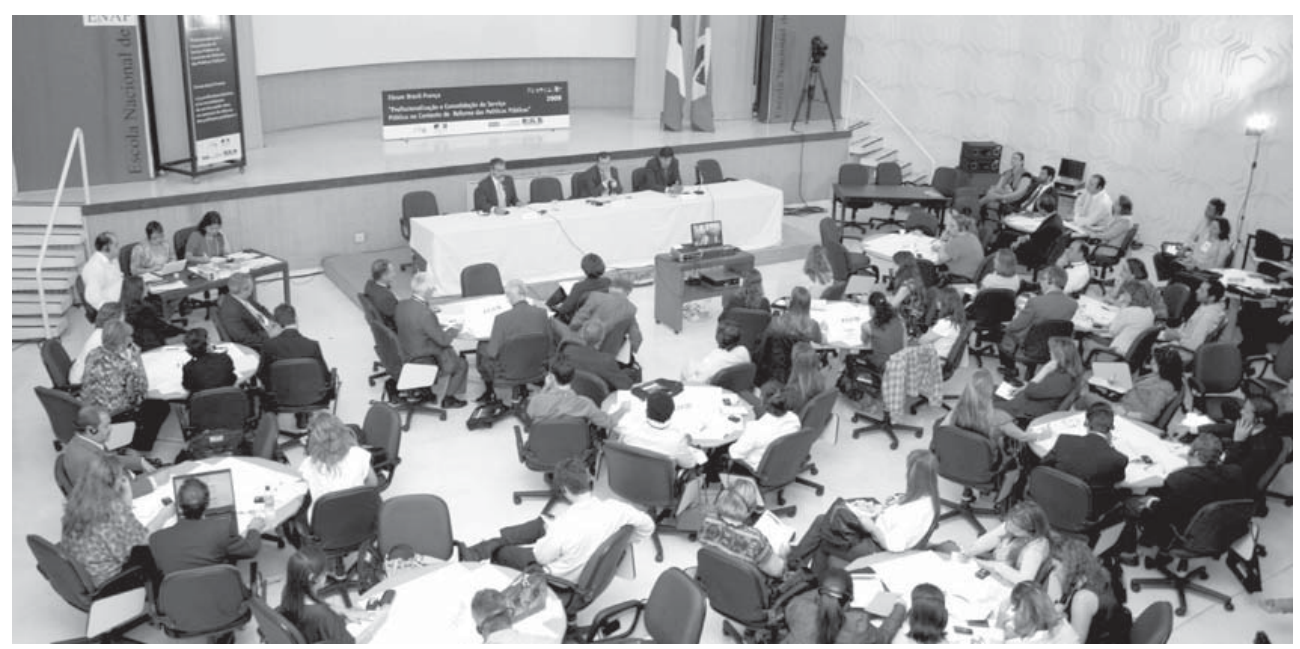

Dirigentes de escolas de governo avaliam a profissionalização do serviço público. 
pensado em duas ideias-chave: democratizar e profissionalizar.

Para Camet, a recente crise financeira mundial confirmou a necessidade de o Estado conservar sua legitimidade, desenvolver parcerias com diferentes atores e atuar como regulador, gerenciando e antecipando esse tipo de situação. "Todos os Estados necessitam de uma função pública competente, democrática e imparcial, que aplique rigorosamente o princípio de neutralidade e de racionalidade", disse.

Em relação aos desafios da formação, Françoise citou a necessidade de que as lideranças públicas se adéquem ao cenário econômico, social e administrativo, cada vez mais movimentado e diversificado. "Esse desafio não corresponde a somente um ministério ou a uma agência e, sim, às regras de uma política interministerial e global", avaliou.

O secretário executivo adjunto do MP, Francisco Gaetani, mencionou uma série de questões que precisam ser reestruturadas no Brasil para que a profissionalização do serviço público aconteça de fato. Segundo ele, o desenho do sistema de carreiras demanda imediata profissionalização e a modalidade de concursos públicos apre- senta falhas de recrutamento que devem ser corrigidas. Gaetani também acredita que as avaliações de desempenho precisam ter a credibilidade retomada e que a alocação de servidores deve ser feita levando em conta as aptidões profissionais.

Para aperfeiçoar a formação do funcionalismo público brasileiro, segundo Gaetani, também há necessidade de mapear competências e processos, estabelecer bases de dados atualizadas e alinhamento de estruturas de incentivos. O secretário alerta para o problema da formação monotemática. "Apostar em um único modelo de profissional pode levar à distorção e a uma série de patologias organizacionais. Esse é o risco de se investir em direções erradas", complementou.

O representante do Ministério do Planejamento reconhece que a administração pública brasileira ainda apresenta muitos problemas para inovar a formação no campo do empreendedorismo e da liderança. Ele destacou, no entanto, o trabalho realizado pela ENAP nos últimos anos, de modo especial, com o Concurso Inovação na Gestão Pública Federal, que premia e divulga ações bem-sucedidas executadas por órgãos públicos.

\section{Parceria entre ENA e ENAP completa 12 anos}

Além de integrar as comemorações do Ano da França no Brasil, o fórum marcou os 12 anos da parceria entre a Escola Nacional de Administração Pública (ENAP) e Ecole Nationale D'Administration (ENA).

A presidente da ENAP, Helena Kerr do Amaral, lembra que a cooperação de sucesso entre as duas escolas vai além da formação de servidores: "Debatemos temas ligados ao fortalecimento da tomada de decisão das lideranças na Presidência da República, à negociação, à formação de consensos e à gestão de crises".

$\mathrm{Na}$ opinião do diretor da ENA, Bernard Boucault, as reflexões promovidas no Fórum Brasil-França se tornaram ainda mais interessantes porque os dois países têm convicções semelhantes em relação aos desafios na área. "Temos história, cultura e quadro institucional diferentes, mas compartilhamos as mesmas missões no que tange aos valores do serviço público no Estado democrático", afirmou, durante a solenidade de abertura do fórum. 
Boucault acredita que há espaço para fortalecer ainda mais a parceria ENAP-ENA e sugere alguns caminhos: desenvolver a cooperação no campo da experiência administrativa internacional; promover a conexão entre as redes que cada escola representa; e estreitar os laços entre servidores dos dois países.

O diretor de Relações Internacionais da ENA, Phillippe Bastellica, considera estratégica a parceria com a escola brasileira: "Ao conhecer uma realidade diferente da nossa e multiplicar os ângulos de visão, acabamos tendo uma melhor compreensão dos desafios, de um modo geral, e um melhor conhecimento de nós mesmos".

\section{ENAP}

\section{Ano de criação: 1986}

Missão: Desenvolver competências de servidores federais para aumentar a capacidade de governo na gestão das políticas públicas.

Atuação: Cursos de desenvolvimento gerencial; capacitações sob medida para órgãos públicos; aperfeiçoamento de carreiras e pós-graduação nas modalidades presencial, a distância ou mista; formação inicial das carreiras de Especialista em Políticas Públicas e Gestão Governamental (EPPGG) e de Analista de Planejamento e Orçamento (APO); edição de publicações sobre Estado, administração pública e gestão governamental; divulgação de soluções de gestão criativas e inéditas por meio do Concurso Inovação na Gestão Pública Federal; cooperação técnica com escolas de governo e centros de capacitação para difusão de cursos; parcerias internacionais para prospecção de temas e métodos educacionais.

Público: Mensalmente, 1,8 mil alunos, em média, participam dos cursos presenciais e a distância oferecidos pela ENAP.

\section{ENA}

Ano de criação: 1945

Missão: Recrutar e formar profissionais que vão contribuir para a evolução das administrações, buscando democratizar o acesso à alta função pública e profissionalizar a formação de lideranças. Atuação: Formação inicial de altos funcionários franceses e europeus, selecionados por meio de concursos públicos; formação contínua e aperfeiçoamento de funcionários franceses e estrangeiros, no quadro de sessões de curta e longa duração; cooperação em matéria de governança pública e de administração em um quadro bilateral ou multilateral, fundado sob parcerias com escolas, administrações, regiões ou países; pesquisa em ciências administrativas apoiadas em publicações especializadas; preparação para os concursos comunitários do Centro dos Estudos Europeus de Estrasburgo.

Público: A cada ano a ENA acolhe cerca de 120 alunos no curso inicial e mais de 2.500 funcionários e quadros dirigentes nos cursos de formação contínua. 